\section{Kidney \\ Blood Pressure \\ Research}

\title{
Primary Aldosteronism and Pregnancy
}

\author{
Tomáš Zelinka Ondřej Petrák Ján Rosa Robert Holaj Branislav Štrauch \\ Jiř́ Widimský Jr. \\ Center for Hypertension, 3rd Medical Department - Department of Endocrinology and \\ Metabolism, First Faculty of Medicine, Charles University and General University Hospital, \\ Prague, Czech Republic
}

\author{
Keywords \\ Primary aldosteronism · Hypertension · Pregnancy · Aldosterone · Adrenalectomy
}

\begin{abstract}
Objective: Primary aldosteronism (PA) may present at younger age and may thus complicate pregnancy. Our aim was to identify female patients in whom PA was diagnosed after pregnancy complicated with hypertension and to analyze possible hypertension-related complications during pregnancy. Methods: We performed retrospective analysis of female patients with PA diagnosed and treated at our Department who were pregnant before the diagnosis of PA. Results: We found 14 patients with PA (age at diagnosis $32.2 \pm 4.2$ years, hypertension duration $5.4 \pm 3.6$ years) suffering from hypertension 3 (IQR 0, 4) years before pregnancy $(6$ patients had hypertension diagnosed during pregnancy). Three subjects were pregnant twice, and 1 patient had been pregnant three times before the final diagnosis of PA was made. Ten subjects delivered by Caesarean section (in 3 cases due to early-onset preeclampsia and 2 subjects due to significantly increased blood pressure), and 9 cases spontaneously (1 subject complicated twice due to late-onset preeclampsia). Preterm delivery occurred in 5 cases - the earliest one in the sixth month of gestation. Subsequent diagnosis of PA (sometimes with a long delay up to a maximum of 12 years) was made on the basis of significantly low potassium values (2.7 $\pm 0.4 \mathrm{mmol} / \mathrm{L} ; 2$ subjects even suffered from muscle cramps) and hypertension (mostly moderate), elevated plasma/serum aldosterone (54.1 $\pm 20.2 \mathrm{ng} / \mathrm{dL}$ ) and suppressed plasma renin activity $(0.4 \pm 0.2 \mathrm{ng} / \mathrm{mL} / \mathrm{h})$ or plasma renin $(1.9 \pm 1.6 \mathrm{ng} / \mathrm{L})$. Thirteen subjects underwent laparoscopic adrenalectomy (in all but 2 cases, diagnosis of a large cortical adenoma [16 $\pm 5.9 \mathrm{~mm}$ ] was made), and 1 subject was classified with bilateral hyperplasia accord-
\end{abstract}




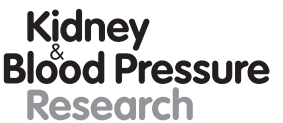

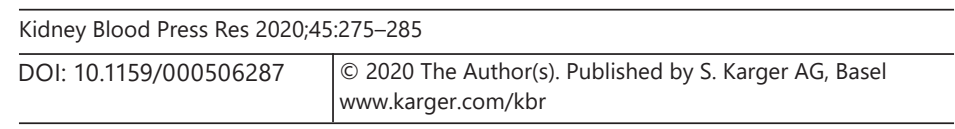

Zelinka et al.: Aldosteronism and Pregnancy

ing to adrenal venous sampling. Operation normalized BP in 10 subjects and improved BP control in the remaining 3 subjects. Two patients became pregnant after adrenalectomy, and their pregnancies were uneventful. Conclusion: PA is associated with a high rate of pregnancy-related complications. The most frequent complication is preeclampsia, in some cases leading to preterm delivery. The optimal prevention of these complications is early diagnosis of PA, and in these particular hypertensive cases, the awareness of hypokalemia.

(C) 2020 The Author(s)

Published by S. Karger AG, Basel

\section{Introduction}

Primary aldosteronism (PA) was first described by Litynsky [1] in 1953, and 2 years later by Conn. It is currently considered as one of the most common causes of secondary hypertension, with an estimated prevalence of approximately 3-6\% in unselected hypertensives $[2,3]$ and about $20 \%$ in subjects with severe hypertension [4]. It is characterized by autonomous aldosterone production with suppressed renin, either from one adrenal (mostly aldosterone-producing adenoma, APA) or from both adrenal glands (mostly bilateral hyperplasia; idiopathic hyperaldosteronism, IHA). It is treated by surgery (unilateral disease) or conservatively with antagonists of mineralocorticoid receptor with subsequent blood pressure (BP) normalization or improvement of hypertension control, depending mostly on patient age, hypertension duration, and severity.

Recent discoveries show that in up to $88 \%$ of adenomas, somatic mutations of genes involved in the regulation of aldosterone synthesis may be found: KCNJ5, CACNA1D, ATP1A1, $A T P 2 B 3$, and CTNNB1 [5]. Mutations of the KCNJ5 gene are found in approximately $35-50 \%$ of APAs and are characterized by excessive hypokalemia, large tumors, and occur more frequently in Asian females and younger subjects [6].

Hypertension may complicate about $10 \%$ of pregnancies. We can therefore speculate that PA may occur in pregnancy more frequently than previously anticipated. In pregnancy, not only all components of the renin angiotensin aldosterone system (RAAS) increase, but also other hormones, such as estrogen or progesterone, which counteract aldosterone action on the mineralocorticoid receptor [7]. All these facts may lead to an unpredictable course of PA during pregnancy, with subsequent BP deterioration.

As case reports or review papers to date have only been focused on PA during pregnancy, our aim was to search for the pregnancy course in female subjects who had diagnosed hypertension either before or during pregnancy and who had subsequently diagnosed PA either as APA or IHA at our institution.

\section{Methods}

For the purpose of this study, we retrospectively reviewed the electronic database of subjects with diagnosed PA in our Hypertension Center, with the following criteria: female gender and diagnosis of hypertension before or during pregnancy. The main reasons for suspected PA were hypokalemia and hypertension.

\section{Diagnosis of PA}

Diagnosis of PA was made based on an elevated aldosterone to renin ratio, with elevated plasma (serum) aldosterone level and suppressed plasma renin activity values or plasma renin levels. For the diagnosis of PA, plasma renin activity was used until 2012, when it was substituted by direct renin measurement [8]. All subjects were switched for at least 2 weeks 


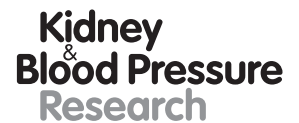

Kidney
Blood Pressure
Research \begin{tabular}{l|l}
\hline Kidney Blood Press Res 2020:45:275-285 \\
\hline DOI: 10.1159/000506287 & $\begin{array}{l}\text { @ 2020 The Author(s). Published by S. Karger AG, Basel } \\
\text { www.karger.com/kbr }\end{array}$ \\
\hline
\end{tabular}

Zelinka et al.: Aldosteronism and Pregnancy

(in the case of spironolactone, 6 weeks) to antihypertensive treatment with verapamil or doxazosin before hormonal testing (serum aldosterone was measured either by commercial RIA or chemiluminescence immunoassay, plasma renin activity by RIA assay, and plasma renin either by RIA or later by chemiluminescence immunoassay). Computed tomography was used for morphological examination of the adrenal glands. In 5 cases, adrenal venous sampling was performed to differentiate between uni- and bilateral forms of PA due to ambiguous finding on CT. Patients with the unilateral disease were scheduled for laparoscopic adrenalectomy, except for 1 patient diagnosed in 1999, in whom open adrenalectomy was performed. Diagnosis of APA was confirmed by histopathology in all subjects who underwent adrenalectomy and further by normalization of kalemia, aldosterone to renin ratio, and either improvement or normalization of BP postoperatively [9]. Hormonal reevaluation was performed mostly immediately postoperatively; BP was checked within 6-12 months postoperatively, either by direct contact or at least by telephonic interview. Three adenomas were subjected to mutational analysis of the KCJN5 gene.

\section{Pregnancy-Related Complications}

Delivery reports from the maternity hospital were used for evaluation of the pregnancy course (pregnancy-related complications: intrauterine growth restriction, preeclampsia), and a detailed pregnancy history was obtained from each subject. Hypertension was evaluated as chronic if occurring until week 20 of pregnancy. Hypertension occurring after 20 weeks of gestation was referred to as gestational hypertension [10]. We considered preeclampsia to be early onset if it occurred before 34 weeks, and late onset if it occurred after week 34 of gestation [11].

\section{Results}

Baseline and Hormonal Characteristics

We identified a total of 14 female patients with PA who presented with hypertension either before or during pregnancy (Table 1). A detailed description of each case is shown in the online supplementary material (see www.karger.com/doi/10.1159/000506287 for all online suppl. material). At the time of PA diagnosis, patients were $32.2 \pm 4.2$ years old and had suffered from hypertension for $5.4 \pm 3.6$ years. The longest interval from the diagnosis of hypertension and the diagnosis of APA was 12 years, the shortest was 5 months. All but 1 subject presented with severe hypokalemia $(2.7 \pm 0.4 \mathrm{mmol} / \mathrm{L}$; the lowest was $1.75 \mathrm{mmol} / \mathrm{L})$. Eight subjects suffered from hypokalemia-related symptoms, mostly muscle weakness or fatigue. Two subjects presented with muscle cramps before the diagnosis of PA was made (patients \#2, \#3 with rhabdomyolysis). Nine subjects presented with moderate hypertension, 3 with severe hypertension and the remaining 2 subjects with mild hypertension.

Hormonal analysis revealed markedly elevated serum aldosterone values and suppressed either plasma renin or plasma renin activity values in all subjects. The final diagnosis of PA in 13 cases was APA, and in 1 subject IHA. Microadenoma was found in only 2 subjects (\#8, \#10); macroadenoma (the largest tumor diameter was $25 \mathrm{~mm}$ ) was diagnosed in the remaining 11 subjects. After tumor removal, plasma potassium values and aldosterone to renin ratio normalized in all subjects. Hypertension improved in 3 subjects and, in the remaining 10 subjects, BP levels normalized (Table 1).

\section{Pregnancy-Related Complications}

Patients were $28.8 \pm 3.8$ years old at the time of pregnancy (patients \#2, 4, and 6 were pregnant twice, patient \#8 three times) and had suffered for $3(0,4)$ years from hypertension 
Kidney

Blood Pressure

Research
Kidney Blood Press Res 2020;45:275-285

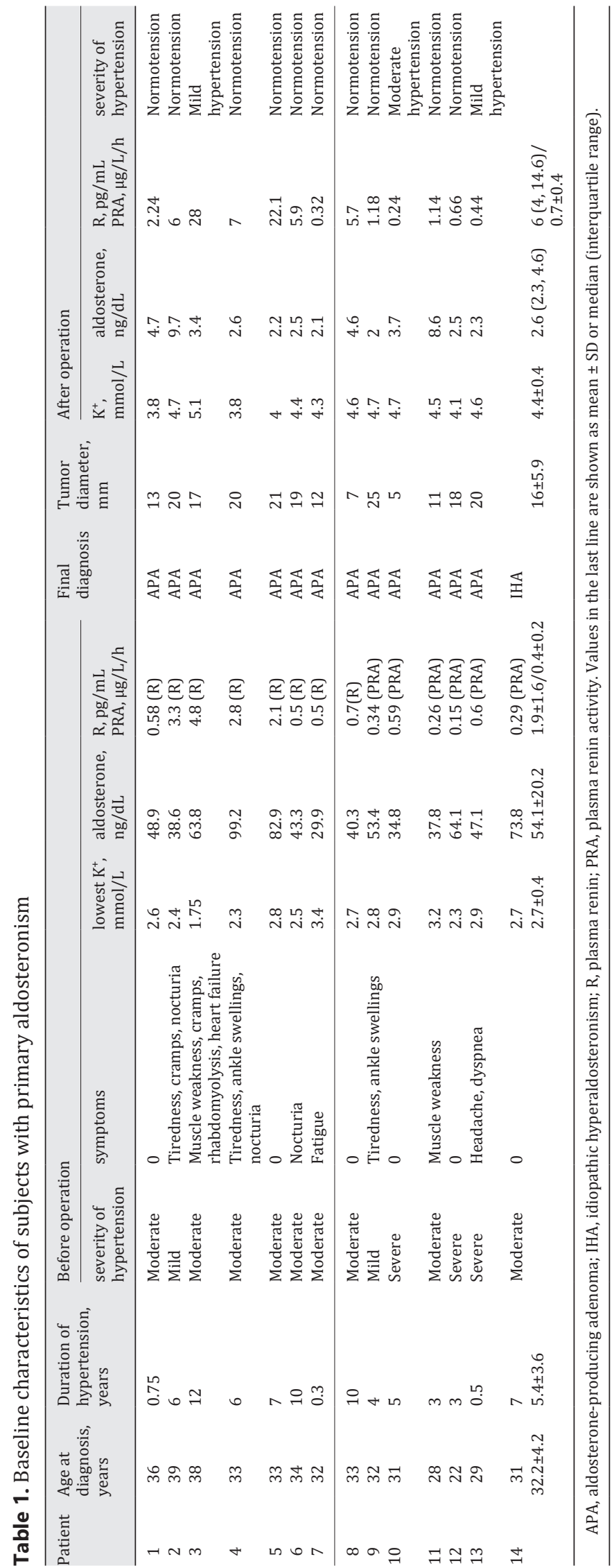




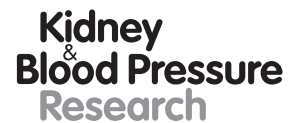

Kidney
Blood Pressure
Research

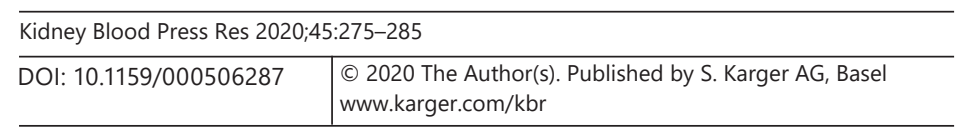

Zelinka et al.: Aldosteronism and Pregnancy

before pregnancy (in 6 subjects, hypertension developed only in pregnancy; the longest interval from hypertension diagnosis to pregnancy was 8 years: patients \#6 and 8). After delivery, hypertension persisted in 12 subjects and, in 2 subjects, was transiently resolved (\#7 and 13) (Table 2).

Fourteen pregnancies were delivered at term, and 5 prematurely (gestational age 27, 29, 33,36 , and 36 weeks). The reason for preterm delivery was early-onset preeclampsia (\#5, \#12, \#14) in 3 cases, significant BP elevation without concomitant proteinuria (\#3) in 1 case, and premature rupture of membranes (\#9) also in 1 case. The remaining subjects delivered spontaneously at term in 7 cases (\#2, 13; twice \#4 and \#8), 3 spontaneously with induction (\#2 at week 40 due to intrauterine growth restriction; \#6 twice due tolate-onset preeclampsia), and 5 subjects by Caesarean section for different reasons (\#1 herpes genitalis, \#7, \#8 breech presentation, \#10 fetal hypoxia and intrauterine growth restriction, \#11 increase in BP).

A favorable hypertension course (= without significant BP increase) was present in 9 pregnancies (\#1, \#2 [twice], \#4 [first pregnancy], \#7, \#8 [three times], and \#13). Significant BP elevation in the second trimester occurred in 4 pregnancies (\#5, \#12, \#14 who developed preterm preeclampsia, and in subject \#6 in her first pregnancy). The remaining 6 pregnancies presented with significant BP increase during the third trimester of gestation - \#3, \#4 (second pregnancy, admission to the hospital 10 days before delivery), \#6 (second pregnancy), and $\# 9$, \#10, and \#11 (Table 2).

In subject \#10, hypokalemia was already known (and supplemented with 3 g potassium chloride during gestation), but examination for secondary cause of hypertension was initiated almost 1 year after delivery. Patient \#5 was followed by a nephrologist for hypokalemia. In subject \#1, hypokalemia was found immediately after the end of puerperium, and a diagnosis of PA was subsequently made. In patient \#7, hypertension reoccurred within 6 months after delivery, which was followed by screening of secondary hypertension.

Targeted molecular tumor examination for the KCJN5 gene was performed in 3 subjects and was positive in all cases: mutation c. $451 \mathrm{G}>\mathrm{A}$ was found in subject \#1 and c.503 T>G in subjects \#2 and \#6. Two patients became pregnant after adrenalectomy, and their pregnancies were uneventful without any BP elevation (\#9 and 11) (Table 2).

\section{Discussion}

In this retrospective study from one institution, we showed a high incidence of hypertension-related pregnancy complications in subjects in whom diagnoses of PA were subsequently made.

On one side, 3 (16\%) of pregnancies developed severe early-onset superimposed preeclampsia, resulting in Caesarean section at gestational age 27, 31, and 33 weeks. A further 7 pregnancies were complicated with BP elevation at the end of pregnancy, leading either to spontaneous delivery with induction, early hospital admission, or Caesarean section. On the other side, only 10 pregnancies presented with mild hypertension without any BP-related complication.

The frequency of pregnancy-related complications in this study is in agreement with previous reports focused on the course of PA during pregnancy, showing the prevalence of preeclampsia in about $25 \%$ of pregnancies, Caesarean section in about $39-44 \%$, or preterm birth in $51 \%[7,12]$. The risk of superimposed preeclampsia in patients with subsequently diagnosed PA may be even higher than in subjects with chronic hypertension with an estimated risk of about $17-25 \%$ [13].

PA is characterized by suppressed renin due to autonomous aldosterone secretion, which is associated with elevated BP levels, hypokalemia, and hypernatremia without concomitant 
Kidney

Blood Pressure

Research
Kidney Blood Press Res 2020;45:275-285 DOI: 10.1159/000506287

C 2020 The Author(s). Published by S. Karger AG, Base www.karger.com/kbr

Zelinka et al.: Aldosteronism and Pregnancy

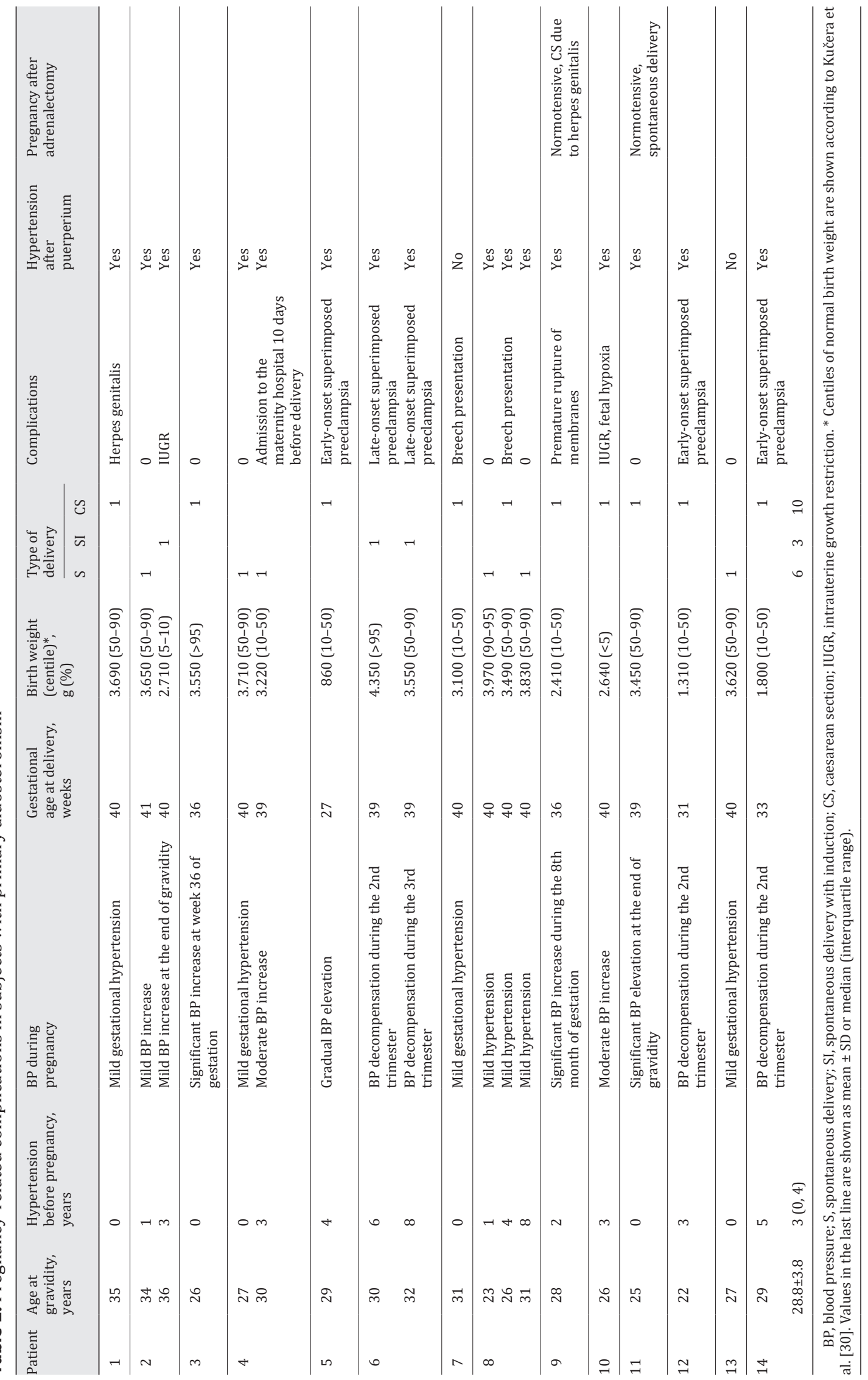




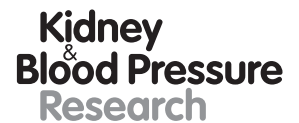

Kidney
Blood Pressure

Research \begin{tabular}{l|l}
\hline Kidney Blood Press Res 2020;45:275-285 \\
\hline DOI: 10.1159/000506287 & $\begin{array}{l}\text { @ 2020 The Author(s). Published by S. Karger AG, Basel } \\
\text { www.karger.com/kbr }\end{array}$ \\
\hline
\end{tabular}

Zelinka et al.: Aldosteronism and Pregnancy

development of edema because of a rise of natriuretic peptides [14, 15]. In pregnancy, we see the activation of the RAAS and its antagonists, nitric oxide/atrial natriuretic peptide. This leads to plasma volume expansion due to continuous natrium retention by the kidney on one side, and to peripheral vasodilatation on the other side to maintain a high rate of placental perfusion for substrate supply and fetal fluid volume balance. Plasma volume expansion and a decrease in systemic vascular resistance associated with BP decrease, and increased renal flow and glomerular filtration are detectable as early as 6 weeks after conception. Since increase in plasma volume expansion is seen throughout a pregnancy, reaching $<30 \%$ above the nonpregnant value [16], systemic vascular resistance reaches its maximal decrease of up to $40 \%$ in the mid-second trimester [17]. BP reaches its nadir at the 20-24th gestational week, with a subsequent increase until the end of pregnancy [18].

During pregnancy, renin is produced not only by the kidney but also by the uterus. The factors regulating renin production by the uterus are unknown. Increased levels of angiotensin II are counterbalanced by decreased responsiveness to angiotensin II, which extends to the renal circulation [19]. Aldosterone levels at the end of pregnancy may increase up to 10 times compared to baseline levels [7]. Despite marked activation, intact RAAS responds appropriately to volume change in pregnant females [20]. The decrease in sodium excretion is mediated by an increased abundance of $\alpha$-subunit of the epithelial sodium channel in the aldosterone-sensitive distal nephron [21]. However, progesterone plays a more significant role in potassium homeostasis, acting as a competitive aldosterone inhibitor on the mineralocorticoid receptor, leading to the increase of potassium reabsorption in the collecting duct [22]. Progesterone action may be counterbalanced by 21-hydroxylation, which leads to a huge increase in natrium-retaining deoxycorticosterone [23].

Preeclampsia contributes to preterm birth and Caesarean delivery, while it is associated with induced early delivery, placental abruption, and fetal growth abnormalities [13]. In preeclampsia, a decrease in RAAS and plasma volume precedes BP elevation [24]. Increased angiotensin II sensitivity is mediated by $\mathrm{AT}_{1}-\mathrm{B}_{2}$ receptor heterodimers, which were detected in preeclampsia [25]. Stimulation of the $\mathrm{AT}_{1}$ receptor may also be mediated by $\mathrm{AT}_{1}$ receptor autoantibodies, which were also detected in preeclampsia and contribute to abnormal uterine perfusion, increased resistance index and placental hypoxia [26]. Elevated levels of these autoantibodies were found in subjects with PA expressing higher titers in APA than in IHA [27]. The course of pregnancy may also be modified by the presence of gonadotropin-releasing hormone/luteinizing hormone-responsive aberrant regulation of aldosterone secretion, which was present in at least 30\% of studied APAs in the study by Gagnon et al. [28].

All subjects presented with a severe form of PA (hypokalemia was present in all subjects; in the vast majority of cases, symptomatic, and in 2 subjects even leading to muscle cramps). Unfortunately, the combination of profound hypokalemia and hypertension was either known but left without further examination (patients were treated with usual antihypertensives and potassium chloride supplementation) or was not diagnosed (general practitioners do not regularly screen for potassium levels even in younger hypertensive subjects in our country). Although hypokalemia is not a sensitive tool for PA screening in the general population [8], we would recommend that checking of potassium levels in all pregnant hypertensive subjects should be performed, in particular in those with moderate and severe hypertension. Those patients with hypokalemia should be referred for further evaluation to Hypertension Centers experienced in PA diagnosis (Fig. 1). Diagnosis of PA during pregnancy may be difficult because of unpredictable renin stimulation due to possible activation of RAAS, which may lead to renin increase and the subsequent decrease of the aldosterone to renin ratio (Fig. 1). The importance of early PA diagnosis with subsequent tumor removal is stressed not only by hypertension cure but also by the normal pregnancy course after APA removal, as shown in 2 cases. 


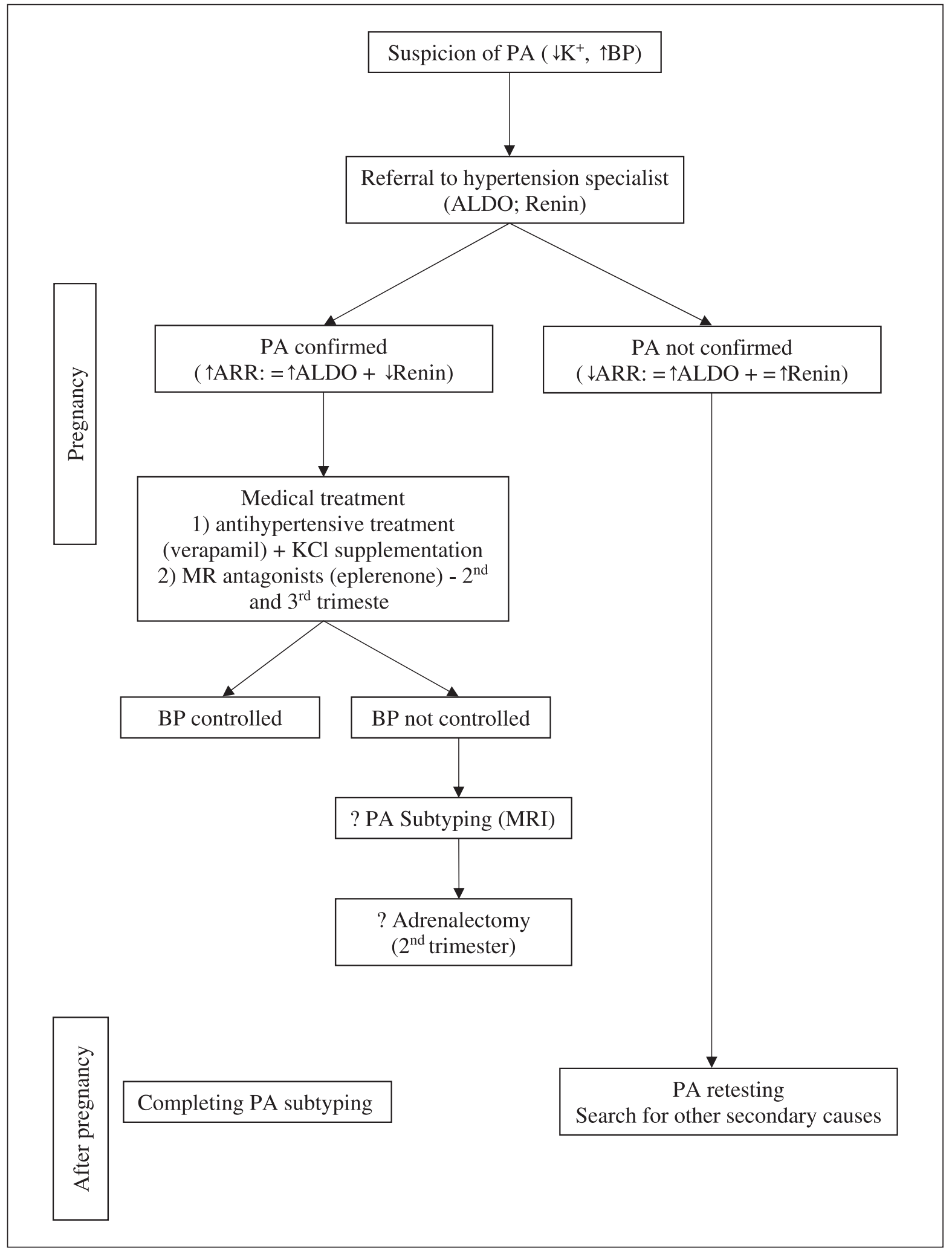

Fig. 1. Flowchart of the diagnosis and treatment of primary aldosteronism during pregnancy. Adapted from Riester and Reincke [29]. ALDO, aldosterone; ARR, aldosterone to renin ratio; BP, blood pressure; $\mathrm{K}^{+}$, potassium; $\mathrm{KCl}$, kalium chloratum; MR, mineralocorticoid receptor; MRI, magnetic resonance imaging; PA, primary aldosteronism. 


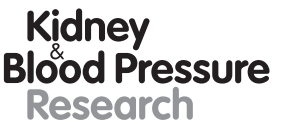

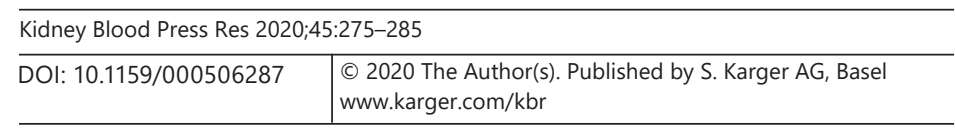

Zelinka et al.: Aldosteronism and Pregnancy

This study has some limitations. Firstly, labeling of pregnancy-related complications was done only from delivery reports which, in the vast majority of cases, are very brief with very limited data available. Secondly, severity of hypertension was judged mostly from a personal history. Thirdly, we have not performed molecular tumor analysis for the presence of somatic mutations systematically, in particular of the KCNJ5 gene which is associated with female gender, younger age, and larger tumor dimension. At least, the preliminary results suggest a high frequency of mutations of the KCJN5 gene in this group of subjects, which corresponds with previous reports.

In conclusion, this study shows the high frequency of BP-related pregnancy complications in subjects who were subsequently diagnosed with PA. APAs were the dominant type of PA in this study. Successful treatment of PA led not only to hypertension improvement or cure, but also to a normal pregnancy course. As all subjects presented with hypokalemia, potassium testing and awareness of PA as a cause of hypertension and hypokalemia would be the best prevention of these pregnancy-related complications. These subjects should be immediately referred to Hypertension Centers experienced in PA diagnosis.

\section{Acknowledgments}

We would like to thank: David Michalský (1st Department of Surgery - Department of Abdominal, Thoracic Surgery and Traumatology, First Faculty of Medicine, Charles University and General University Hospital, Prague, Czech Republic) and Květoslav Novák (Department of Urology, First Faculty of Medicine, Charles University and General University Hospital, Prague, Czech Republic) for surgical treatment of primary aldosteronism; Jaroslava Dušková (Institute of Pathology, First Faculty of Medicine, Charles University in Prague and General University Hospital, Prague, Czech Republic) for histological examinations; Zdeněk Musil (Institute of Biology and Medical Genetics, First Faculty of Medicine, Charles University in Prague and General University Hospital, Prague, Czech Republic) for performing genetic analyses; and Lubomíra Forejtová and Jan Kaván (Department of Radiology, First Faculty of Medicine, Charles University in Prague and General University Hospital, Prague, Czech Republic) for adrenal venous sampling.

\section{Statement of Ethics}

All patients gave their informed consent for inclusion in the study. As this study reports only routine patient care, no approval of the Ethical Commission of our institution was necessary according to Czech Law.

\section{Disclosure Statement}

The authors have nothing to disclose.

\section{Funding Sources}

This study was supported by research projects of the Charles University Progres Q25 and Q28 and by research grant of the Ministry of Health of the Czech Republic \# NV19-01-00083. 


\section{Kidney \\ Blood Pressure Research}

\begin{tabular}{l|l}
\hline Kidney Blood Press Res 2020;45:275-285 \\
\hline DOI: 10.1159/000506287 & $\begin{array}{l}\text { @ 2020 The Author(s). Published by S. Karger AG, Basel } \\
\text { www.karger.com/kbr }\end{array}$ \\
\hline
\end{tabular}

Zelinka et al.: Aldosteronism and Pregnancy

\section{Author Contributions}

T.Z.: data acquisition, data analysis, writing, and manuscript editing; O.P., J.R., R.H., B.Š., J.W.: data acquisition, and manuscript editing.

\section{References}

1 Litynski M. Hypertension caused by tumors of the adrenal cortex. Pol Tyg Lek (Wars). 1953 Feb;8(6):204-8.

2 Käyser SC, Deinum J, de Grauw WJ, Schalk BW, Bor HJ, Lenders JW, et al. Prevalence of primary aldosteronism in primary care: a cross-sectional study. Br J Gen Pract. 2018 Feb;68(667):e114-22.

3 Monticone S, Burrello J, Tizzani D, Bertello C, Viola A, Buffolo F, et al. Prevalence and Clinical Manifestations of Primary Aldosteronism Encountered in Primary Care Practice. J Am Coll Cardiol. 2017 Apr;69(14):181120.

4 Štrauch B, Zelinka T, Hampf M, Bernhardt R, Widimský J Jr. Prevalence of primary hyperaldosteronism in moderate to severe hypertension in the Central Europe region. J Hum Hypertens. 2003 May;17(5):349-52.

5 Nanba K, Omata K, Else T, Beck PC, Nanba AT, Turcu AF, et al. Targeted Molecular Characterization of Aldosterone-Producing Adenomas in White Americans. J Clin Endocrinol Metab. 2018 Oct;103(10):3869-76.

6 Dutta RK, Söderkvist P, Gimm O. Genetics of primary hyperaldosteronism. Endocr Relat Cancer. 2016 Oct; 23(10):R437-54.

7 Landau E, Amar L. Primary aldosteronism and pregnancy. Ann Endocrinol (Paris). 2016 Jun;77(2):148-60.

8 Funder JW, Carey RM, Mantero F, Murad MH, Reincke M, Shibata H, et al. The Management of Primary Aldosteronism: Case Detection, Diagnosis, and Treatment: An Endocrine Society Clinical Practice Guideline. J Clin Endocrinol Metab. 2016 May;101(5):1889-916.

9 Rossi GP, Bernini G, Caliumi C, Desideri G, Fabris B, Ferri C, et al; PAPY Study Investigators. A prospective study of the prevalence of primary aldosteronism in 1,125 hypertensive patients. J Am Coll Cardiol. 2006 Dec; 48(11):2293-300.

10 Brown MA, Magee LA, Kenny LC, Karumanchi SA, McCarthy FP, Saito S, et al; International Society for the Study of Hypertension in Pregnancy (ISSHP). Hypertensive Disorders of Pregnancy: ISSHP Classification, Diagnosis, and Management Recommendations for International Practice. Hypertension. 2018 Jul;72(1):24-43.

11 Tranquilli AL, Brown MA, Zeeman GG, Dekker G, Sibai BM; Statements from the International Society for the Study of Hypertension in Pregnancy (ISSHP). The definition of severe and early-onset preeclampsia. Pregnancy Hypertens. 2013 Jan;3(1):44-7.

12 Quartermaine G, Lambert K, Rees K, Seed PT, Dhanjal MK, Knight M, et al. Hormone-secreting adrenal tumours cause severe hypertension and high rates of poor pregnancy outcome; a UK Obstetric Surveillance System study with case control comparisons. BJOG. 2018 May;125(6):719-27.

13 Seely EW, Ecker J. Chronic hypertension in pregnancy. Circulation. 2014 Mar;129(11):1254-61.

14 Opocher G, Rocco S, Carpené G, Vettoretti A, Cimolato M, Mantero F. Usefulness of atrial natriuretic peptide assay in primary aldosteronism. Am J Hypertens. 1992 Nov;5(11):811-6.

15 Pizzolo F, Zorzi F, Chiecchi L, Consoli L, Aprili I, Guarini P, et al. NT-proBNP, a useful tool in hypertensive patients undergoing a diagnostic evaluation for primary aldosteronism. Endocrine. 2014 Apr;45(3):479-86.

16 Salas SP, Marshall G, Gutiérrez BL, Rosso P. Time course of maternal plasma volume and hormonal changes in women with preeclampsia or fetal growth restriction. Hypertension. 2006 Feb;47(2):203-8.

17 Chapman AB, Abraham WT, Zamudio S, Coffin C, Merouani A, Young D, et al. Temporal relationships between hormonal and hemodynamic changes in early human pregnancy. Kidney Int. 1998 Dec;54(6):2056-63.

18 James PR, Nelson-Piercy C. Management of hypertension before, during, and after pregnancy. Heart. 2004 Dec; 90(12):1499-504.

19 Novak J, Reckelhoff J, Bumgarner L, Cockrell K, Kassab S, Granger JP. Reduced sensitivity of the renal circulation to angiotensin II in pregnant rats. Hypertension. 1997 Sep;30(3 Pt 2):580-4.

20 Weinberger MH, Kramer NJ, Grim CE, Petersen LP. The effect of posture and saline loading on plasma renin activity and aldosterone concentration in pregnant, non-pregnant and estrogen-treated women. J Clin Endocrinol Metab. 1977 Jan;44(1):69-77.

21 Masilamani S, Kim GH, Mitchell C, Wade JB, Knepper MA. Aldosterone-mediated regulation of ENaC alpha, beta, and gamma subunit proteins in rat kidney. J Clin Invest. 1999;104:R19-23.

22 West CA, Sasser JM, Baylis C. The enigma of continual plasma volume expansion in pregnancy: critical role of the renin-angiotensin-aldosterone system. Am J Physiol Renal Physiol. 2016 Dec;311(6):F1125-34.

23 Winkel CA, Milewich L, Parker CR Jr, Gant NF, Simpson ER, MacDonald PC. Conversion of plasma progesterone to deoxycorticosterone in men, nonpregnant and pregnant women, and adrenalectomized subjects. J Clin Invest. 1980 0ct;66(4):803-12.

24 Brown MA, Gallery ED. Volume homeostasis in normal pregnancy and pre-eclampsia: physiology and clinical implications. Baillieres Clin Obstet Gynaecol. 1994 Jun;8(2):287-310.

25 AbdAlla S, Lother H, el Massiery A, Quitterer U. Increased AT(1) receptor heterodimers in preeclampsia mediate enhanced angiotensin II responsiveness. Nat Med. 2001 Sep;7(9):1003-9. 
26 Herse F, LaMarca B. Angiotensin II type 1 receptor autoantibody (AT1-AA)-mediated pregnancy hypertension. Am J Reprod Immunol. 2013 Apr;69(4):413-8.

27 Rossitto G, Regolisti G, Rossi E, Negro A, Nicoli D, Casali B, et al. Elevation of angiotensin-II type-1-receptor autoantibodies titer in primary aldosteronism as a result of aldosterone-producing adenoma. Hypertension. 2013 Feb;61(2):526-33.

28 Gagnon N, Cáceres-Gorriti KY, Corbeil G, El Ghoyareb N, Ludwig N, Latour M, et al. Genetic Characterization of GnRH/LH-Responsive Primary Aldosteronism. J Clin Endocrinol Metab. 2018 Aug;103(8):2926-35.

29 Riester A, Reincke M. Progress in primary aldosteronism: mineralocorticoid receptor antagonists and management of primary aldosteronism in pregnancy. Eur J Endocrinol. 2015 Jan;172(1):R23-30.

30 Kučera J, Kubelík J, Melichar J, Štembera Z, Velebil P, Kučerová I. New Birth Weight Charts for the Czech Republic. Českoslov Pediatr. 1999;54:572-578. 